\title{
Prevalence of ADHD in a sample of Italian students: A population-based study
}

\author{
Rio Bianchini ${ }^{\mathrm{a}, 1}$, Valentina Postorino ${ }^{\mathrm{b}, 1}$, Rita Grasso $^{\mathrm{a}}$, Bartolo Santoro ${ }^{\mathrm{a}}$, \\ Salvatore Migliore ${ }^{a}$, Corrado Burlò ${ }^{\mathrm{a}}$, Carmela Tata ${ }^{\mathrm{a}}$, Luigi Mazzone ${ }^{\mathrm{b}, *}$ \\ ${ }^{a}$ Azienda Sanitaria Provinciale di Siracusa, Service of Child Neuropsychiatry, Via Bianca Sebastiano, 47, Siracusa, Italy \\ ${ }^{\mathrm{b}}$ I.R.C.C.S. Children's Hospital Bambino Gesù, Department of Neuroscience, Child Neuropsychiatry Unit, Square S. Onofrio 4, 00165 Rome, \\ Italy
}

\section{A R T I C L E I N F O}

\section{Article history:}

Received 4 March 2013

Received in revised form 12 May 2013

Accepted 13 May 2013

Available online 7 June 2013

\section{Keywords:}

Prevalence

Attention deficit disorder with hyperactivity

Children

Adolescents

Epidemiology

\begin{abstract}
A B S T R A C T
Attention-deficit/hyperactivity disorder (ADHD) is one of the most common diagnosis for children and adolescents, although the reported estimates for prevalence are extremely variable worldwide. In the present work we investigate the prevalence of ADHD in a sample of Italian students in a study divided in two phases. In Phase I, a total of 6183 schoolchildren (3178 males and 3005 females, aged range 5-15 years) were screened using the SDAI rating scale for teachers. In Phase II, the parents of children and adolescents who met high screen criteria according to SDAI (cut-off $>14 ; n=471,7.3 \%$ ) were invited to complete a specific clinical-diagnostic assessment for ADHD with the help of an experienced clinician. Within the entire sample, 107 children dropped out and 12 had mental retardation, whereas 332 subjects (278 males and 54 females, age range 5-14 years) completed the Phase II of the study. One hundred ninety subjects ( 163 males and 27 females, male: female ratio 6:1, mean age 8 years) were diagnosed with ADHD, indicating a prevalence of $3 \%$. ADHD subtypes included the following: combined ( $n=108 ; 56.8 \%)$, inattentive $(n=48 ; 25.2 \%)$ and hyperactive/impulsive $(n=33 ; 17.3 \%)$.

Our findings are in line with other reports of ADHD prevalence in the European Countries, and may contribute to underline the impact of this phenomenon in the population, and the need of achieving an improvement in the quality of the public health mental service for the prevention and treatment of ADHD.
\end{abstract}

(c) 2013 Elsevier Ltd. All rights reserved.

\section{Introduction}

Attention-deficit/hyperactivity disorder (ADHD) is one of the most common diagnosis worldwide for children and adolescents and, according to DSM-IV-TR, it is characterized by pervasive and impairing symptoms of inattention, hyperactivity and impulsivity (APA, 2000; Biederman \& Faraone, 2005; Swanson et al., 1998). ADHD comprises a broad spectrum of clinical manifestations highly heterogeneous in terms of presence and level of symptoms. Longitudinal studies showed that ADHD is not restricted to childhood and adolescence, but it tends to persist also in adulthood, although with

\footnotetext{
* Corresponding author. Tel.: +39 0668592734.

E-mail address: gigimazzone@yahoo.it (L. Mazzone).

1 These authors contributed equally to this work.
} 
variable rates across the lifespan (Biederman et al., 2000, 2006; Cahill et al., 2012; Hill \& Schoener, 1996; Simon, Czobor, \& Bitter, 2012).

Studies published so far, have reported highly variable rates for ADHD prevalence worldwide during childhood and adolescence, ranging from $0.9 \%$ to $20 \%$, raising concerns about the consistency of estimates and the validity of diagnoses (Bener, Qahtani, \& Abdelaal, 2006; Cardo, Servera, \& Llobera-Canaves, 2007; Cornejo et al., 2005; de la Barra, Vicente, Saldivia, \& Melipillan, 2012; Goodman et al., 2005; Harzke et al., 2012; Montiel, Pen, Montiel-Barbero, \& Polanczyk, 2008; Skounti, Philalithis, \& Galanakis, 2007; Skounti, Philalithis, Mpitzaraki, Vamvoukas, \& Galanakis, 2006; Wolraich et al., 2012). Overall, the reported rates for ADHD prevalence are lower for Europe as compared to North America, and this brought many authors to hypothesize that the ADHD may be typical of the western countries as a result of some demographic characteristics (Anderson, 1996; Bird, 2002; Timimi \& Taylor, 2004). However, it has to be pointed out that all the studies have applied different methodologies, including rating scales and checklists, as well as diagnostic interviews, and this may represent another possible explanation for these discrepancies (Faraone, Sergeant, Gillberg, \& Biederman, 2003; Swanson et al., 1998; Timimi, 2005). Indeed, this variability would likely disappear by applying similar instruments, as suggested by a review study on epidemiology of ADHD across the lifespan showing similar estimates for North America and Europe upon adjustment for methodological issues (5.29\%) (Polanczyk \& Rohde, 2007). From other studies, an incidence of ADHD, ranging from 5.29\% to 7.5\%, was found in different socio-cultural settings, such as Switzerland, Brazil, England, Holland, Venezuela, Taiwan, and Congo (Ford, Goodman, \& Meltzer, 2003; Gau, Chong, Chen, \& Cheng, 2005; Kashala, Tylleskar, Elgen, Kayembe, \& Sommerfelt, 2005; Rohde et al., 1999; Steinhausen, Metzke, Meier, \& Kannenberg, 1998).

To our knowledge, only three studies so far were conducted in Italy, reporting variable prevalence rates (Frigerio et al., 2009, 2006; Mugnaini et al., 2006). Specifically, Mugnaini et al. (2006), evaluating 1891 first-graders, aged 6.6-7.4 years, throughout teacher rating scales and without a specific clinical-diagnostic assessment for ADHD, reported an ADHD rate of 7.1\%. On the other hand, Frigerio et al. (2009), in the preadolescent mental health project (PrISMA), evaluated 3418 adolescents, aged 10-14 years, throughout parents rating scales for the prevalence of mental disorders at large, and estimated a much lower rate of externalizing disorders (1.2\%).

Studies in children consistently suggest that the ADHD prevalence is higher in boys than in girls with a male to female ratio from 3:1 to 9:1, depending on the origin of the sample ascertainment: indeed, the prevalence in girls seems to be higher in community samples than in clinical samples (Staller \& Faraone, 2006). The impact of ethnic and socio-economic issues on the ADHD prevalence rates has not been extensively addressed.

ADHD can often be found in comorbidity with other psychiatric disorders. Indeed, a recent study on the prevalence of psychiatric disorders in young children, showed that $12.5 \%$ of 4 -years-olds had at least one psychiatric disorder, and that when a child had an ADHD, an oppositional defiant disorder, a conduct disorder or a depressive disorder, it was more likely than not that she or he had another emotional or behavioral disorder in comorbidity (Wichstrom et al., 2011).

Finally, an epidemiological study on pharmacologically treated ADHD children, adolescents and adults in the UK, revealed a trend of increasing prescription of ADHD treatment drugs over the period 2003-2008 for all age groups, further highlighting the urgent need to deeply investigate the prevalence of this disorder in order to plan appropriate treatment strategies (McCarthy et al., 2012).

The aim of the present study was to investigate ADHD prevalence in a sample of Italian students, at first, by using a screening for attention deficit and hyperactivity/impulsivity symptoms completed by teachers, and afterwards, by applying a more specific clinical-diagnostic assessment for ADHD, completed by children, parents and teachers with the help of an experienced clinician.

\section{Materials and methods}

\subsection{Sampling population of Phase I}

During Phase I of the study, children attending primary and middle schools were submitted to a screening for attention deficit and hyperactivity/impulsivity symptoms. All elementary and middle schools ( 36 schools for 9151 children) in the urban area of Syracuse (Italy) were asked to participate. Out of them, 24 schools agreed to the study, whereas 12 schools (6 elementary and 6 middle) did not participate: a total of 6183 schoolchildren (3178 males and 3005 females, age range 5-15 years) were, therefore, included in the study. The informed consent, during Phase I, was not required because the primary aim of this phase was to assess the health status of the population.

\subsection{Phase I: screening for attention deficit and hyperactivity/impulsivity symptoms}

For every schoolchild, the teachers were asked to fill out the "SDAI" Rating Scale (ADHD Rating Scale for Teachers [Scala per $i$ Disturbi di Attenzione/Iperattività per Insegnanti]), for the presence of ADHD symptoms (Cornoldi, Gardinale, Masi, \& Pattenò, 1996; Cornoldi \& Marzocchi, 2000). The SDAI is a 18-item four-point Likert scale, requiring the teacher to rate the child frequency/intensity of symptoms (from $0=$ no problem to $3=$ severe problem). The SDAI includes three subscales: one for Inattentive symptoms, one for Hyperactive/Impulsive symptoms, and one for Inattention and Hyperactive Combined symptoms. Conventionally, a score above 14 , with a mean score of 1.5 , for the three subscales, indicates a high presence of symptoms. The SDAI scale has been validated and standardized for the Italian population and shows an interrater reliability 
of 0.80 and 0.74 , for the Inattentive subscale and the Hyperactive/Impulsive subscale, respectively. The test-retest reliability is 0.83 and 0.81 , for Inattentive and Hyperactive/Impulsive, respectively (Cornoldi \& Marzocchi, 2000).

Data from teachers were used to identify the subjects eligible for Phase II of the study: children resulting above the cut-off ( $>14)$ for ADHD symptoms, as evaluated by SDAI, were classified as "high screen" and included in Phase II.

\subsection{Sampling procedure of Phase II}

The school staff contacted the families whose children were categorized as "high screen" (SDAI cut-off $>14$ ), and requested a written informed consent to participate in the study. Families who returned their permission to participate in the study ( $n=451)$ were invited to take part into the clinical-diagnostic phase (Phase II) at the Child and Adolescent Psychiatric Unit of Syracuse, where children, parents and teachers completed a clinical-diagnostic assessment for ADHD symptoms with an experienced clinician. This assessment started on September 2010 and ended on December 2011. A total of 332 children ( $73.6 \%$ of those invited) participated in Phase II. A flow-chart describing the recruitment procedure and the participation rates is depicted in Fig. 1.

\subsection{Phase II: clinical-diagnostic assessment to evaluate the presence of Attention-deficit/hyperactivity disorder (ADHD)}

The Schedule for Affective Disorders and Schizophrenia for School-Age Children/Present and Lifetime Version (K-SADS-PL) was completed by all the children and parents included in the study with an experienced trained clinician (Kaufman et al., 1997). The K-SADS-PL is a semi-structured psychiatric interview that ascertains both lifetime and current diagnostic status based on DSM-IV-TR criteria (APA, 2000). The K-SADS-PL includes three components: introductory interview (demographic, health, and other background information), screen interview (82 symptoms related to 20 diagnostic areas), and five diagnostic supplements including affective disorders (major depression, dysthymia, mania, hypomania), psychotic disorders, anxiety disorders (social phobia, agoraphobia, specific phobia, obsessive-compulsive disorder, separation anxiety disorder, generalized anxiety disorder, panic disorder, post-traumatic stress disorder), disruptive behavioral disorders (attention deficit and hyperactivity disorder, conduct disorder, oppositional defiant disorder),substance abuse, and other disorders (tic disorders, eating disorders, and elimination disorders). The skip-out criteria in the screen interview specify which sections of the supplements, if any, should be completed. The Italian version of this tool has been shown to have good psychometric properties, as demonstrated by an excellent interrater reliability of 0.80 , for the age group between 6 and 17 years. Indeed, a recent study (Birmaher et al., 2009) have established the psychometric properties of the K-SADS-PL in preschool children (aged 2-5 years,) reporting an excellent discriminant validity (a $p$-value $\leq 0.02$ for ADHD), and an excellent internal consistency of Cronbach's $\alpha$ ranging between 0.80 and 0.90 .

The Swanson, Nolan and Pelham Scale-Version IV (SNAP-IV) was completed by teachers and parents (Bussing et al., 2008; Swanson et al., 2001). This is a 26 -item questionnaire, in a 4-point Likert scale, that is used to evaluate ADHD symptoms and severity. The 26 items include 18 items for ADHD symptoms ( 9 for Inattentive, 9 for Hyperactive/Impulsive), and 8 items for

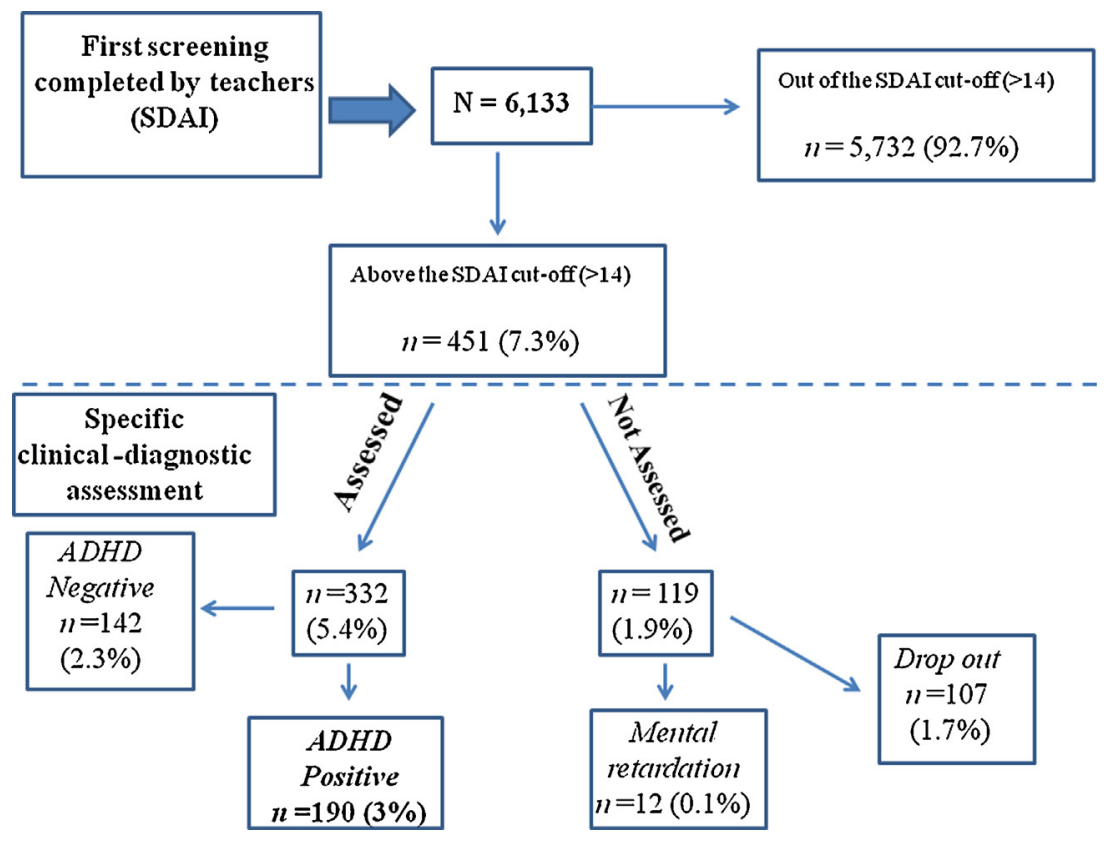

Fig. 1. Recruitment procedure and participation rates. 
oppositional defiant disorder (ODD) symptoms, as defined in the DSM-IV-TR. Each item is rated on a 0-3 score scale $(0=$ not at all, 1 = just a little, 2 = quite a bit and 3 =very much). The SNAP-IV consists of the Inattention, Hyperactive/Impulsive, Inattention and Hyperactive/Impulsive Combined, and Oppositional subscales. Each subscale has a different cut-off score that can be considered indicative of clinical impairment: 1.78 for Inattention subscale, 1.44 for Hyperactive/Impulsive subscale, 1.67 for Inattention and Hyperactive/Impulsive Combined, and 1.88 for Oppositional Defiant Disorder. The SNAP-IV has been shown to have a good internal consistency for all domains (Inattentive: $\alpha=0.88-0.89$, Hyperactive/Impulsive: $\alpha=0.76-0.80$, and Oppositional Defiant Disorder: $\alpha=0.87-0.90$ ) (Bussing et al., 2008).

All the subjects were examined by an experienced clinician, and the diagnoses of ADHD were established following the three different definitions of impairment, as stated in the DSM-IV-TR criteria (APA, 2000).

Moreover, all the children were assessed for cognitive function by the Italian validated version of Wechsler Intelligence Scale for Children-III (WISC-III) (Orsini \& Picone, 1995; Wechsler, Golombok, \& Rust, 1992). The WISC-III comprises 10 subtests ( 5 verbal and 5 performance subtests) that sum to the Verbal Intelligence Quotient and Performance Intelligence Quotient, and produce a Full-Scale Intelligence Quotient. Scores were age standardized according to the Italian validated version of the WISC-III manual.

Finally, to evaluate the presence of comorbidity with a Specific Learning Disorder, the children were assessed with the Battery for Evaluating Dyslexia and Dysorthography (DDE), and the M.T. reading test (Cornoldi \& Colpo, 1998; Sartori, Job, \& Tressoldi, 1995). The DDE comprises 12 tests ( 9 to evaluate reading abilities and 3 to assess writings abilities). On each test, the examiner should note reading accuracy, determined by the number of correctly decoded words, and test execution speed, measured by the relationship between the total number of syllables read and total time in seconds. The M.T. reading test is a text, varying for each grade and phase of the scholastic year (initial, middle and final), that the participants are asked to read. Errors made and time needed to read the entire text are taken into account. For each text, normative data, means, standard deviations, and percentiles were provided.

\subsection{Data analysis}

The data were analyzed using the statistical software package SPSS, Version 16.0. Descriptive analyses were used, and variables are presented as either mean \pm standard deviation (SD), or frequency. Prevalence rates were calculated on the total number of children assessed. An interrater reliability analysis using the Kappa statistic was performed to determine consistency among DSM-IV-TR criteria and K-SADS-PL diagnoses. Group comparisons (ADHD versus non-ADHD) were conducted using chisquare test for categorical variables (gender), and analysis of covariance (ANCOVA) for continuous variables (age and IQ). For binary variables the effect size is provided as odds ratio, whereas for continuous or discrete variables as difference between means. The degree of uncertainty around each effect size is provided in terms of $95 \%$ confidence interval. Comparisons within the ADHD group for categorical variables were performed using chi-square tests. An alpha level of 0.05 was set for statistical significance.

\section{Results}

\subsection{Phase I: screening for attention deficit and hyperactivity/impulsivity symptoms}

The teachers completed the SDAI for a total of 6183 Caucasian schoolchildren (age range 5-15 years, mean age 8.9 years), 3178 of whom were males (51.4\%) and 3005 females (48.6\%). Three thousand, seven hundred and thirty-two children resulted out of the SDAI cut-off ( $>14$ ), whereas 451 children, corresponding to $7.3 \%$ of total, were above the cut-off (mean age 8.3 years, age range from 5 to 14 years). Among them, 356 were males (78.9\%), and 95 were females (21.0\%), and 55 ( $12.7 \%$ of the 451 children) benefitted from a scholastic support. In more detail, the SDAI results for these 451 children showed that 248 of them (204 males and 44 females) were above the cut-off for "Inattentive and Hyperactive/Impulsive Combined symptoms" (54.9\%), 162 (127 males and 35 females) for "Inattentive symptoms" (35.9\%), and 41 (25 males and 16 females) for "Hyperactive/Impulsive symptoms" (9.0\%). None of the participants had ever used any psychotropic medication at the time of the study. The demographic characteristics of the children included in the survey are summarized in Table 1.

Table 1

Demographic characteristics of the total sample.

\begin{tabular}{lll}
\hline Groups & Total screened schoolchildren $\left(N=6183^{\mathrm{a}}\right)$ & Schoolchildren above the SDAI ${ }^{\mathrm{b}}$ cut-off $(N=451)$ \\
\hline Gender & $3178(51.4)$ & $356(78.9)$ \\
Males $N(\%)$ & $3005(48.6)$ & $95(21.0)$ \\
Females $N(\%)$ & $5-15(8.9)$ & $8-14(8.3)$ \\
Age range (mean) & & \\
\hline
\end{tabular}

\footnotetext{
a Number of subjects.

b ADHD rating scale for teachers.
} 
Table 2

Comparisons of demographic characteristics of children with ADHD versus children without ADHD.

\begin{tabular}{|c|c|c|c|c|}
\hline Groups & ADHD children $\left(N=190^{\mathrm{a}}\right)$ & Non-ADHD children $(N=142)$ & $p$ & Effect size \\
\hline \multicolumn{3}{|l|}{ Gender } & \multicolumn{2}{|l|}{ NS ${ }^{b}$} \\
\hline Males $N(\%)$ & $163(85.7)$ & $115(80.9)$ & & $1.42(0.79-2.54)^{\mathrm{c}}$ \\
\hline Females $N(\%)$ & $27(14.2)$ & $27(19.0)$ & & $0.71(0.39-1.27)$ \\
\hline Age $\left(\right.$ mean $\left.\pm \mathrm{SD}^{\mathrm{d}}\right)$ & $8.0 \pm 2.30$ & $8.1 \pm 2.14$ & NS & $-0.10(-0.59 ; 0.39)^{\mathrm{e}}$ \\
\hline $\mathrm{IQ}^{\mathrm{f}}($ mean $\pm \mathrm{SD})$ & $87.54 \pm 9.59$ & $88.16 \pm 9.43$ & NS & $-0.62(-2.70 ; 1.46)$ \\
\hline \multicolumn{5}{|c|}{ a Number of subjects. } \\
\hline \\
\hline \multicolumn{5}{|c|}{$\begin{array}{l}\text { Not significant for } p>0.05 \text {. } \\
\text { c For binary variables the effect size (ADHD versus non-ADHD children) is provided as odds ratio and } 95 \% \text { confidence interval. }\end{array}$} \\
\hline \multicolumn{5}{|c|}{ d Standard deviation. } \\
\hline \multicolumn{5}{|c|}{ e For continuous variables the effect size is given as difference between means and $95 \%$ confidence interval of the corresponding point estimate. } \\
\hline
\end{tabular}

\subsection{Phase II: clinical-diagnostic assessment to evaluate the presence of Attention-deficit/hyperactivity disorder (ADHD)}

Among the 451 children and adolescents that scored above the cut-off for SDAI symptoms, 332 subjects (278 males and 54 females, age range 5-14 years, mean age 8.4 years) were submitted to the specific clinical-diagnostic assessment for ADHD, whereas 119 were excluded, either because they dropped out $(n=107)$, or had a mental retardation $(n=12$, Full-Scale IQ $<70$ assessed with WISC-III). All the subjects were evaluated by an experienced children and adolescents psychiatrist according to DSM-IV-TR ADHD criteria. Moreover, all the parents and children completed the $K-S A D S-P L$ with a trained clinician. An interrater reliability analysis using the Kappa statistic was performed to determine consistency among DSM-IV-TR criteria and $K$-SADS-PL diagnoses, returning an almost perfect agreement (Kappa $=0.913, p<0.001$ ). Finally, ADHD diagnosis was considered completed by symptoms positivity in the SNAP-IV teachers and parents version.

One hundred ninety subjects out of the 332 tested (163 males and 27 females, with a male: female ratio of 6:1, mean age of 8 years) resulted positive for ADHD, corresponding to a prevalence of 3\%. ADHD subtypes included the following: combined ( $n=108 ; 56.8 \%)$; inattentive $(n=48 ; 25.2 \%)$; hyperactive/impulsive $(n=33 ; 17.3 \%)$.

Gender $\left(X^{2}: 3.742, p=0.293\right)$, age (F: .718, $\left.p=0.709\right)$ and IQ (F: 2.328, $\left.p=0.554\right)$ distribution were similar between children with $(n=190)$ and without $(n=142)$ diagnosis of ADHD (Table 2$)$. Accordingly, analysis carried out by calculating the effect size showed that the $95 \%$ confidence interval of each point estimates, crossed one for binary variables and zero for continuous or discrete variables, indicating no significant associations between gender, age, IQ, and the presence/absence of ADHD diagnosis (Table 2).

Analysis of comorbidities revealed that 143 children (75.2\%) affected by ADHD had a comorbidity with one other disorder, In more detail, the following disorders were found in comorbidity: Oppositional Defiant Disorder $(n=42)$, Specific Learning Disorder $(n=36)$, Conduct Disorder $(n=22)$, Generalized Anxiety Disorder $(n=17)$, Depressive Disorder $(n=9)$, a different comorbid diagnosis (such as Tourette Syndrome, Tic Disorders, Eating Disorder and Enuresis) $(n=17)$. Moreover, of these 143 children, 47 (24.7\%) had two comorbid disorders. Specifically: Oppositional Defiant Disorder $(n=20)$, Specific Learning Disorder $(n=10)$, Generalized Anxiety Disorder $(n=4)$, a different comorbid diagnosis (such as Tourette Syndrome, Tic Disorders, Eating Disorder and Enuresis) $(n=13)$.

No significant differences were found between ADHD males $(n=163)$ and females $(n=27)$ according to age, IQ, ADHD subtypes, comorbidity, SDAI subscales, SNAP-IV Parents and Teachers version. The clinical characteristics of the subjects with ADHD are shown in Table 3.

\section{Discussion}

Epidemiological studies on ADHD prevalence during childhood and adolescence have reported highly variable rates worldwide, ranging from 0.9\% to 20\% (Bener et al., 2006; Cardo et al., 2007; Cornejo et al., 2005; de la Barra et al., 2012; Goodman et al., 2005; Harzke et al., 2012; Montiel et al., 2008; Skounti et al., 2007, 2006; Wolraich et al., 2012). In our sample, $3 \%$ of the screened children and adolescents met the criteria for ADHD, indicating a slightly lower rate as compared to the ADHD worldwide pooled prevalence of 5.29\% (Faraone et al., 2003; Polanczyk, de Lima, Horta, Biederman, \& Rohde, 2007). However, our results are in line with other epidemiological reports investigating the prevalence of ADHD in Europe, which is generally lower than in North America (Faraone et al., 2003; Polanczyk et al., 2007). The DSM-IV-TR reports that ADHD prevalence rates vary from $3 \%$ to $5 \%$, whereas studies based on the ADHD DSM-IV-TR criteria report a proportion of children affected by ADHD ranging from 3.7\% to 8.9\%, with lower rates when applying a more rigorous impairment criterion (APA, 2000; Baumgaertel, Wolraich, \& Dietrich, 1995; Canino et al., 2004; Wolraich, Hannah, Pinnock, Baumgaertel, \& Brown, 1996). Moreover, ADHD prevalence seems to depend on the source evaluating the symptoms (Breton et al., 1999; Magnusson, Smari, Gretarsdottir, \& Prandardottir, 1999; Stanger \& Lewis, 1993). For instance, Breton et al. (1999) reported estimate rates varying from 3.3\% to $5 \%$ and $8.9 \%$, according to children's, parents', and teachers' reports, respectively. In our study, diagnosis of ADHD required the three different definitions of impairment, as stated in the DSM-IV-TR. Furthermore, to be in receipt of an ADHD diagnosis, different tools, such as $K-S A D S-P L$, and SNAP-IV, completed by different sources (children, 
Table 3

Distribution of ADHD subtypes, comorbidity and clinical characteristics of the ADHD group.

\begin{tabular}{|c|c|c|c|}
\hline & Males $\left(N=163^{\mathrm{a}}\right)$ & Females $(N=27)$ & Total $(N=190)$ \\
\hline $\mathrm{IQ}^{\mathrm{b}}($ mean $\pm \mathrm{SD})$ & $87.82 \pm 9.62$ & $85.89 \pm 9.44$ & $87.54 \pm 9.59$ \\
\hline \multicolumn{4}{|l|}{ Subtypes of $A D H D$} \\
\hline Inattentive $N(\%)$ & $38(20.0)$ & $11(5.8)$ & $49(25.8)$ \\
\hline Hyperactive/Impulsive $N(\%)$ & $27(14.2)$ & $6(3.2)$ & $33(17.4)$ \\
\hline Combined $N(\%)$ & $98(51.6)$ & $10(5.3)$ & $108(56.8)$ \\
\hline \multicolumn{4}{|l|}{ SDAIC subscales } \\
\hline Inattentive (mean $\pm S D)^{d}$ & $19.87 \pm 5.49$ & $18.89 \pm 4.72$ & $19.73 \pm 5.39$ \\
\hline Hyperactive/Impulsive (mean \pm SD) & $16.82 \pm 6.92$ & $13.67 \pm 8.37$ & $16.37 \pm 7.20$ \\
\hline Combined $($ mean $\pm S D)$ & $36.68 \pm 9.19$ & $32.56 \pm 9.27$ & $36.09 \pm 9.29$ \\
\hline \multicolumn{4}{|l|}{ SNAP-IV-parents ${ }^{\mathrm{e}}$ subscales } \\
\hline Inattentive (mean $\pm \mathrm{SD}$ ) & $2.03 \pm 0.50$ & $2.04 \pm 0.39$ & $2.03 \pm 0.49$ \\
\hline Hyperactive/Impulsive (mean \pm SD) & $1.88 \pm 0.62$ & $1.67 \pm 0.69$ & $1.85 \pm 0.63$ \\
\hline Combined (mean \pm SD) & $3.91 \pm 0.74$ & $3.71 \pm 0.68$ & $3.88 \pm 0.73$ \\
\hline \multicolumn{4}{|l|}{ SNAP-IV-teachers ${ }^{\mathrm{f}}$ subscales } \\
\hline Inattentive (mean $\pm \mathrm{SD}$ ) & $2.48 \pm 0.48$ & $2.47 \pm 0.32$ & $2.48 \pm 0.46$ \\
\hline Hyperactive/Impulsive (mean \pm SD) & $1.77 \pm 0.61$ & $1.54 \pm 0.72$ & $1.74 \pm 0.63$ \\
\hline Combined (mean $\pm \mathrm{SD})$ & $4.26 \pm 9.19$ & $4.02 \pm 0.67$ & $4.22 \pm 0.72$ \\
\hline
\end{tabular}

a Number of subjects.

b Intelligence quotient.

c SDAI-ADHD rating scale for teachers.

d Standard deviation.

e Swanson, Nolan and Pelham Scale-Version IV for parents.

f Swanson, Nolan and Pelham Scale-Version IV for teachers.

parents and teachers) had to result positive for ADHD symptoms all at once. Therefore, the lower prevalence that we found in our sample could be due to the rigorous exclusionary methodology.

To our knowledge, our study is the first epidemiological survey on ADHD in a large sample of Italian children and adolescents. The preadolescent mental health project (PrISMA), described by Frigerio et al. (2009) evaluated adolescents for the prevalence of mental disorders in general, and Mugnaini et al. (2006), reporting an ADHD prevalence of 7.1\%, applied only teachers' reports, without a specific clinical-diagnostic assessment for ADHD. Indeed, this percentage is similar to the rate that we found by teachers' reports in the first phase of our study (7.3\%) (Frigerio et al., 2009, 2006; Mugnaini et al., 2006).

Moreover, these surveys were carried out in the North of Italy, whereas the children included in our study were attending schools in the South (Sicily), indicating that there may be dissimilarities also according to cultural and geographical differences.

The results reported in our study are in line with those by other studies, in terms of prevalence of ADHD subtypes (combined more frequent, and hyperactive/impulsive less frequent), gender ratio (6:1), and presence of a comorbid internalizing or externalizing disorder (Baumgaertel et al., 1995; Biederman et al., 2002; Ersan, Dogan, Dogan, \& Somer, 2004; Frigerio et al., 2006; Gomez, Harvey, Quick, Scharer, \& Harris, 1999; Graetz, Sawyer, Hazell, Arney, \& Baghurst, 2001; Kashala et al., 2005; Staller \& Faraone, 2006; Timimi, 2005; Wolraich et al., 1996; Wolraich, Hannah, Baumgaertel, \& Feurer, 1998).

Our findings have to be interpreted in light of certain limitations. First, we did not analyze the negative predictive value of the screening test used, which could have been evaluated by including in Phase II of the study a certain number of children that had scored negatively on SDAI within Phase I. Second, children from only one region of the country were included. Third, participant selection was conducted throughout schools, rather than public registers, due to the Italian personal data privacy law, which not allow public registers to be viewed (DL 30 July 1999, n. 281 and 282), and fourth, socio-economic status and parental education variables were not considered, although the schools included in the study represented areas of both high and low socio-economic status.

\section{Conclusion}

In conclusion, besides to these limitations, our study has added a new insight into the existing knowledge on ADHD prevalence, documenting the rates of a European country for which these data were missing. Shed light on the epidemiology of ADHD is a fundamental issue for researchers in order to better define methodological and conceptual problems that need to be further addressed. Moreover, these results underline the importance of applying a screening methodology in the school context that could easily be applied to other mental disorders and the need of developing a thorough assessment. Finally, understanding the impact of ADHD in the general population, may also help the clinicians to develop an adequate service, in terms of both psychological screening, and treatment procedure, and possibly to prevent the onset of other disorders in comorbidity during lifespan. 


\section{Funding source}

No external funding was secured for this study.

\section{Financial disclosure}

The authors have no financial relationships relevant to this article to disclose.

\section{Conflict of interest}

The authors have no conflicts of interest to disclose.

\section{References}

American Psychiatric Association. (2000). Diagnostic and statistical manual of mental disorders(4th edn., text revision). Washington, DC.

Anderson, J. C. (1996). Is childhood hyperactivity the product of western culture? Lancet, 348, 73-74.

Baumgaertel, A., Wolraich, M., \& Dietrich, M. (1995). Comparison of diagnostic criteria for ADHD in a German elementary school sample. Journal of the American Academy of Child and Adolescent Psychiatry, 34, 629-638.

Bener, A., Qahtani, R. A., \& Abdelaal, I. (2006). The prevalence of ADHD among primary school children in an Arabian society. Journal of Attention Disorders, 10, 77-82.

Biederman, J., \& Faraone, S. V. (2005). Attention-deficit hyperactivity disorder. Lancet, 366, 237-248.

Biederman, J., Mick, E., \& Faraone, S. V. (2000). Age-dependent decline of symptoms of attention deficit hyperactivity disorder: Impact of remission definition and symptom type. American Journal of Psychiatry, 157, 816-818.

Biederman, J., Mick, E., Faraone, S. V., Braaten, E., Doyle, A., Spencer, T., et al. (2002). Influence of gender on attention deficit hyperactivity disorder in children referred to a psychiatric clinic. American Journal of Psychiatry, 159, 36-42.

Biederman, J., Monuteaux, M. C., Mick, E., Spencer, T., Wilens, T. E., Silva, J. M., et al. (2006). Young adult outcome of attention deficit hyperactivity disorder: A controlled 10-year follow-up study. Psychological Medicine, 36, 167-179.

Bird, H. R. (2002). The diagnostic classification, epidemiology and cross-cultural validity of ADHD in attention deficit hyperactivity disorder: State of the science: Best practices. Kingston: Civic Research Institute.

Birmaher, B., Ehmann, M., Axelson, D. A., Goldstein, B. I., Monk, K., Kalas, C., et al. (2009). Schedule for Affective Disorders and Schizophrenia for School-Age Children (K-SADS-PL) for the Assessment of Preschool Children - A preliminary psychometric study. Journal of Psychiatric Research, 43, $680-686$.

Breton, J. J., Bergeron, L., Valla, J. P., Berthiaume, C., Gaudet, N., Lambert, J., et al. (1999). Quebec child mental health survey: Prevalence of DSM-III-R mental health disorders. Journal of Child Psychology and Psychiatry, 40, 375-384.

Bussing, R., Fernandez, M., Harwood, M., Wei, H., Garvan, C. W., Eyberg, S. M., et al. (2008). Parent and teacher SNAP-IV ratings of attention deficit hyperactivity disorder symptoms: Psychometric properties and normative ratings from a school district sample. Assessment, 15, 317-328.

Cahill, B. S., Coolidge, F. L., Segal, D. L., Klebe, K. J., Marle, P. D., \& Overmann, K. A. (2012). Prevalence of ADHD and its subtypes in male and female adult prison inmates. Behavioral Science and Law, 30, 154-166.

Canino, G., Shrout, P. E., Rubio-Stipec, M., Bird, H. R., Bravo, M., Ramirez, R., et al. (2004). The DSM-IV rates of child and adolescent disorders in Puerto Rico: Prevalence, correlates, service use and the effects of impairment. Archives of General Psychiatry, 61, 85-93.

Cardo, E., Servera, M., \& Llobera-Canaves, J. (2007). Estimation of the prevalence of attention deficit hyperactivity disorder among the standard population on the island of Majorca. Review of Neurology, 44, 10-14.

Cornejo, J. W., Osío, O., Sánchez, Y., Carrizosa, J., Sánchez, G., Grisales, H., et al. (2005). Prevalence of attention deficit hyperactivity disorder in Colombian children and teenagers. Review of Neurology, 40, 716-722.

Cornoldi, C., \& Colpo, G. (1998). Prove Di Lettura M T Per la Scuola Elementare. Firenze: Giunti Organizzazioni Speciali.

Cornoldi, C., Gardinale, M., Masi, A., \& Pattenò, L. (1996). Impulsività e autocontrollo: Interventi e tecniche cognitive. Trento: Erickson.

Cornoldi, C., \& Marzocchi, G. M. (2000). Una scala di facile uso per la rilevazione dei comportamenti problematici dei bambini con Deficit di Attenzione e Iperattività. Psicologia Clinica dello Sviluppo, 1, 43-62.

de la Barra, F. E., Vicente, B., Saldivia, S., \& Melipillan, R. (2012). Epidemiology of ADHD in Chilean children and adolescents, ADHD. Attention Deficit and Hyperactivity Disorders, 5, 1-8.

Ersan, E. E., Dogan, O., Dogan, S., \& Somer, H. (2004). The distribution of symptoms of attention-deficit/hyperactivity disorder and oppositional defiant disorder in school age children in Turkey. European Child and Adolescent Psychiatry, 13, 354-361.

Faraone, S. V., Sergeant, J., Gillberg, C., \& Biederman, J. (2003). The worldwide prevalence of ADHD: Is it an American condition? World Psychiatry, 2, 104-113.

Ford, T., Goodman, R., \& Meltzer, H. (2003). The British child and adolescent mental health survey 1999: The prevalence of DSM IV disorders. Journal of American Academy Child and Adolescent Psychiatry, 42, 1203-1211.

Frigerio, A., Rucci, P., Goodman, R., Ammaniti, M., Carlet, O., Cavolina, P., et al. (2009). Prevalence and correlates of mental disorders among adolescents in Italy: The PrISMA study. European Journal of Child and Adolescent Psychiatry, 18, 217-226.

Frigerio, A., Vanzin, L., Pastore, V., Nobile, M., Giorda, R., Marino, C., et al. (2006). The Italian Preadolescent Mental Health Project (PrISMA): Rationale and methods. International Journal of Methods and Psychiatric Research, 15, 22-35.

Gau, S. S., Chong, M. Y., Chen, T. H., \& Cheng, A. T. (2005). A 3-year panel study of mental disorders among adolescents in Taiwan. American Journal of Psychiatry, 162, 1344-1350.

Gomez, R., Harvey, J., Quick, C., Scharer, I., \& Harris, G. (1999). DSM-IV AD/HD: Confirmatory factor models, prevalence and gender and age differences based on parent and teacher ratings of Australian primary school children. Journal of Child Psychology and Psychiatry, 40, 265-274.

Goodman, R., Neves dos Santos, D., Robatto Nunes, A. P., Pereira de Miranda, D., Fleitlich-Bilyk, B., \& Almeida Filho, N. (2005). The Ilha de Mare study: A survey of child mental health problems in a predominantly African-Brazilian rural community. Society of Psychiatry and Psychiatric Epidemiology, $40,11-17$.

Graetz, B. W., Sawyer, M. G., Hazell, P. L., Arney, F., \& Baghurst, P. (2001). Validity of DSM-IV ADHD subtypes in a nationally representative sample of Australian children and adolescents. Journal of American Academy Child and Adolescent Psychiatry., 40, 1410-1417.

Harzke, A. J., Baillargeon, J., Baillargeon, G., Henry, J., Olvera, R. L., Torrealday, O., et al. (2012). Prevalence of psychiatric disorders in the Texas juvenile correctional system. Journal Correct Health Care, 18, 143-157.

Hill, J. C., \& Schoener, E. P. (1996). Age-dependent decline of attention deficit hyperactivity disorder. American Journal of Psychiatry, 153, 1143-1146.

Kashala, E., Tylleskar, T., Elgen, I., Kayembe, K. T., \& Sommerfelt, K. (2005). Attention deficit and hyperactivity disorder among school children in Kinshasa Democratic Republic of Congo. African Health Sciences, 5, 172-181.

Kaufman, J., Bismaher, B., Brent, D. A., Rao, U., Flynn, C., Moreci, P., et al. (1997). Schedule for Affective Disorders and Schizophrenia for School-Aged Children Present and Lifetime Version (K-SADS-PL): Initial reliability and validity data. Journal of American Academy of Child and Adolescent Psychiatry, 36, 980-988.

Magnusson, P., Smari, J., Gretarsdottir, H., \& Prandardottir, H. (1999). Attention-Deficit/Hyperactivity symptoms in Icelandic schoolchildren: Assessment with the Attention Deficit/Hyperactivity rating scale-IV. Scandinavian Journal of Psychology, 40, 301-306. 
McCarthy, S., Wilton, L., Murray, M. L., Hodgkins, P., Asherson, P., \& Wong, I. C. K. (2012). The epidemiology of pharmacologically treated attention deficit hyperactivity disorder (ADHD) in children, adolescents and adults in UK primary care. BMC Pediatrics, $12,78$.

Montiel, C., Pen, J. A., Montiel-Barbero, I., \& Polanczyk, G. (2008). Prevalence rates of attention deficit/hyperactivity disorder in a school sample of Venezuelan children. Children Psychiatry and Human Development, 39, 311-322.

Mugnaini, D., Masi, G., Brovedani, P., Chelazzi, C., Matas, M., Romagnoli, C., et al. (2006). Teacher reports of ADHD symptoms in Italian children at the end of first grade. European Psychiatry, 21, 419-426.

Orsini, A., \& Picone, L. (1995). WISC-III. Contributo alla taratura italiana. Firenze: Giunti Organizzazioni Speciali.

Polanczyk, G., de Lima, M. S., Horta, B. L., Biederman, J., \& Rohde, L. A. (2007). The worldwide prevalence of ADHD: A systematic review and metaregression analysis. American Journal of Psychiatry, 164, 943-948.

Polanczyk, G., \& Rohde, A. (2007). Epidemiology of attention-deficit/hyperactivity disorder across the lifespan. Current Opinion in Psychiatry, $20,386-392$.

Rohde, L. A., Biederman, J., Busnello, E. A., Zimmermann, H., Schmitz, M., Martins, S., et al. (1999). ADHD in a school sample of Brazilian adolescents: A study of prevalence, comorbid conditions and impairments. Journal of the American Academy of Child and Adolescent Psychiatry, 38, $716-722$.

Sartori, G., Job, R., \& Tressoldi, P. E. (1995). Batteria per la valutazione della dislessia e della disortografia evolutiva. Firenze: Giunti Organizzazioni Speciali.

Simon, V., Czobor, P., \& Bitter, I. (2012). Is ADHD severity in adults associated with the lifetime prevalence of comorbid depressive episodes and anxiety disorders? European Psychiatry, 14.

Skounti, M., Philalithis, A., \& Galanakis, E. (2007). Variations in prevalence of attention deficit hyperactivity disorder worldwide. European Journal of Pediatrics, 166, $117-123$.

Skounti, M., Philalithis, A., Mpitzaraki, K., Vamvoukas, M., \& Galanakis, E. (2006). Attention-deficit/hyperactivity disorder in schoolchildren in Crete. Acta Paediatrica, 95, 658-663.

Steinhausen, H. C., Metzke, C. W., Meier, M., \& Kannenberg, R. (1998). Prevalence of child and adolescent psychiatric disorders: The Zurich Epidemiological Study. Acta Psychiatrica Scandinava, 98, 262-271.

Staller, J., \& Faraone, S. V. (2006). Attention-deficit hyperactivity disorder in girls: Epidemiology and management. CNS Drugs, 20 , 107-123.

Stanger, C., \& Lewis, M. (1993). Agreement among parents' teachers and children on internalizing and externalizing behavior problems. Journal of Clinical Child and Psychology, 22, 107-115.

Swanson, J. M., Kraemer, H. C., Hinshaw, S. P., Arnold, L. E., Conners, C. K., Abikoff, H. B., et al. (2001). Clinical relevance of the primary findings of the MTA: Success rates based on severity of ADHD and ODD symptoms at the end of treatment. Journal of American Academy of Child and Adolescent Psychiatry, 40, 168-179.

Swanson, J. M., Sergeant, J. A., Taylor, E., Sonuga-Barke, E. J., Jensen, P. S., \& Cantwell, D. P. (1998). Attention-deficit hyperactivity disorder and hyperkinetic disorder. Lancet, 351, 429-433.

Timimi, S. (2005). Effect of globalization on children's mental health. British Medical Journal, 331, 37-39.

Timimi, S., \& Taylor, E. (2004). ADHD is best understood as a cultural construct. British Journal Psychiatry, 184, 8-9.

Wechsler, D., Golombok, S., \& Rust, J. (1992). Manual for the Wechsler intelligence scale for children. London: The Psychological Corporation.

Wichstrom, L., Berg-Nielsen, T. S., Angold, A., Egger, H. L., Solheim, E., \& Sveen, T. H. (2011). Prevalence of psychiatric disorders in preschoolers. Journal of Child Psychology and Psychiatry, 10, 1-11.

Wolraich, M. L., Hannah, J. N., Baumgaertel, A., \& Feurer, I. D. (1998). Examination of DSM-IV criteria for attention deficit/hyperactivity disorder in a county-wide sample. Journal of Developmental and Behavioral Pediatrics, 19, 162-168.

Wolraich, M., Hannah, J., Pinnock, T., Baumgaertel, A., \& Brown, J. (1996). Comparison of diagnostic criteria for attention-deficit hyperactivity disorder in a countywide sample. Journal of American Academy of Child and Adolescent Psychiatry, 35, 319-324.

Wolraich, M. L., McKeown, R. E., Visser, S. N., Bard, D., Cuffe, S., Neas, B., et al. (2012). The prevalence of ADHD: Its diagnosis and treatment in four school districts across two states. Journal of Attention Disorders, 21, 3-13. 